\title{
Peningkatan Pengetahuan Siswa-Siswi Sebagai Alternative Ketahanan Siap Kerja Dalam Menghadapi MEA pada SMK Nurul Falah Pekanbaru
}

\author{
WITA DWIKA LISTIHANA ${ }^{1}$, DINI ONASIS ${ }^{2}$, AFVAN AQUINO $^{3}$ \\ Universitas Lancang Kuning \\ Jln. Yos Sudarso KM 08 Rumbai Telp. (0761) 52581 \\ E-mail : dinionasis@unilak.ac.id
}

\begin{abstract}
The commitment to realize the ASEAN Economic Community is characterized by the enactment of the flow of goods and services among ASEAN countries will be free to cross the boundaries of the State physically and administratively, without any obstacle. The presence of the MEA brings great opportunities to all ASEAN employees and certainly brings with it a number of opportunities and challenges. 4 (four) of the majors owned by SMK Nurul Falah educate, print and give birth to skilled workers, but graduates of these four majors will be threatened its existence in the world of work with the existence of free competition for existence existence MEA. Therefore, the importance of Preparation and Understanding is solid and strong in the students of Vocational High School Nurul Falah in anticipating and facing the MEA. SMK Nurul Falah asks TIM from Faculty of Economics of University of Lancang Kuning to fill the empty space they face, this empty space will be filled by TIM from Faculty of Economics of University of Lancang Kuning in giving knowledge enhancement about MEA as alternative of ready worker in facing MEA at SMK Nurul Falah Pekanbaru. Through community service activities will be given a solution to the problems of partners above. That is : Provide to Partner knowledge and deeper understanding of the recent Changes to MEA. Giving to Partners the knowledge and understanding of the readiness and resilience students must have in facing the MEA. Giving to Partners the knowledge and understanding of weaknesses, strengths, opportunities and threats that students have in facing the MEA. Students and students know MEA in general, but do not know and understand MEA deeply. Understanding of the knowledge and insights and skills that must be prepared and owned by students should start from the school year in vocational school.

Students should have the skills and competencies beyond those obtained in schools to sharpen their competitive ability with the MEA free trade market.
\end{abstract}

Keywords: MEA, the knowledge, insights, skills

Masyarakat Ekonomi ASEAN (MEA) atau ASEAN Economic Community (AEC) merupakan kesepakatan negara-negara ASEAN dalam rangka mewujudkan visi ASEAN 2020. MEA adalah salah satu komunitas dari 3 komunitas ASEAN. 2 komunitas lainnya adalah di bidang keamanan politik dan sosial budaya. Membentuk kawasan perdagangan bebas. Untuk meningkatkan daya saing ekonomi kawasan ASEAN. Menjadikan ASEAN sebagai basis produksi dunia dan menciptakan pasar regional bagi penduduk ASEAN.

Komitmen mewujudkan Masyarakat Ekonomi ASEAN dicirikan dengan berlakunya arus barang dan jasa di antara negara-negara ASEAN akan bebas dapat melintasi batas-batas Negara secara fisik dan administrasi, tanpa sesuatu hambatan apapun. Pelaksanaan MEA akan menghilangkan hambatan aliran barang, investasi dan jasa diantara negara ASEAN.Tujuan utama dari program liberalisasi perdagangan di lingkungan Negara-negara ASEAN adalah untuk kesejahteraan dan kemakmuran rakyat yang ada di negara ASEAN, namun apabila tidak siap maka justru akan membawa dampak yang merugikan. Kunci utama dalam menghadapi ASEAN ini adalah peningkatan kompetensi Sumber Daya Manusia Indonesia agar dapat memanfaatkan keunggulan 
komparatif menjadi keunggulan kompetitif, dengan upaya peningkatan daya saing SDM nasional.

Dalam blue print MEA, terdapat empat prioritas dalam kerangka MEA, yaitu:

1. Adanya arus barang dan jasa yang bebas (free flow food and services)

2. Ekonomi regional yang kompetitif (competitive economic region)

3. Perkembangan ekuitas ekonomi (equitable economic development)

4. Integrasi memasuki ekonomi global (full integration into global economy) (Suatma, 2012)

Adanya MEA membawa kesempatan besar bagi semua tenaga kerja warga negara ASEAN dan tentunya membawa sejumlah peluang dan tantangan. Sebagai contoh, seseorang yang berwarga Negara Indonesia dapat bekerja di Singapura, Thailand, Malaysia, Filipina, Vietnam dan lain-lain. Secara kuantitatif, Indonesia memiliki keunggulan dibandingkan beberapa negara lain, sehingga dapat memaksimalkan kesempatan ini. Namun di sisi lain, Indonesia akan dihadapkan dengan berbagi ancaman apabila Sumber Daya Manusia (SDM) belum siap. Artinya peluang kerja akan diambil oleh tenaga kerja asing dan Indonesia akan menjadi penonton di negeri sendiri.

Lebih spesifiknya MEA membuka pasar bebas tenaga kerja profesional. Ada delapan profesi yang dibuka (free of skill labour) saat MEA mulai bergulir yaitu insinyur, arsitek, perawat, tenaga survei, tenaga pariwisata, praktisi medis, dokter gigi, dan akuntan. Dibukanya delapan profesi tersebut untuk tenaga asing berpotensi mendorong peningkatan pengangguran dari kalangan terdidik

Sekolah menengah Kejuruan (SMK) Nurul Falah sebagai mitra pengabdian memiliki jurusan atau kompetensi keahlian sebagai berikut :

1. Teknik Komputer dan Jaringan

2. Akomodasi Perhotelan

3. Akuntansi
4. Administrasi Perkantoran

5. Bisnis Manajemen

4 (empat) dari jurusan yang dimiliki oleh SMK Nurul Falah mendidik, mencetak dan melahirkan tenaga kerja yang terampil, namun lulusan atas keempat jurusan ini akan terancam keberadaannya didunia kerja dengan adanya persaingan bebas atas existensi keberadaan MEA.

Oleh sebab itu pentingnya Persiapan dan Pemahaman yang kokoh dan kuat pada siswa-siswi Sekolah Menengah Kejuruan Nurul Falah dalam mengantisipasi dan menghadapi MEA tersebut.

Mitra SMK Nurul Falah sejauh ini menguatkan pendidikan dan ketrampilan terhadap anak didik namun tidak menekankan pada pentingnya pemahaman MEA.

melihat

Melalui wawancara awal serta Visi dan Misi yang dimiliki oleh SMK Nurul Falah maka TIM didapati oleh TIM bahwa SMK Nurul Falah tidak menekankan atas persaingan Global, SMK Nurul Falah menekankan pada pendidikan dan ketrampilan untuk persaingan kerja yang ada di lokal, padahal dengan adanya MEA maka Pasar Lokal akan berubah menjadi pasar Global.

Oleh sebab itulah maka SMK Nurul Falah meminta TIM dari Fakultas Ekonomi Universitas Lancang Kuning untuk dapat mengisi ruang kosong yang mereka hadapi, ruang kosong inilah yang akan diisi oleh TIM dari Fakultas Ekonomi Universitas Lancang Kuning dalam memberikan peningkatan pengetahuan tentang MEA sebagai alternative ketahanana siap kerja dalam menghadapi MEA pada SMK Nurul Falah Pekanbaru.

Objek pengabdian ini adalah Siswa dan siswi yang masih berada di kelas 1 tujuannya adalah untuk dapat mengenal dan memahami MEA jauh lebih awal dan mereka dapat mempersiapkan diri jauh dari awal sejak kelas 1 SMK. 
Penguatan juga diberikan kepada Siswa-siswi mengenai Akuntansi dan Ketrampilan Akuntansi yang wajib dan harus mereka kuasai, dalam menghadapi MEA ini.

Berdasarkan latar berlakang diatas maka kami TIM dari Fakultas Ekonomi Universitas Lancang Kuning melaksanakan pengabdian dengan judul "Peningkatan Pengetahuan siswa-siswi tentang Masyarakat Ekonomi Asean (MEA) sebagai alternative ketahanan siap kerja dalam menghadapi MEA pada SMK Nurul Falah Pekanbaru".

Melalui identifikasi dan komunikasi dengan SMK Nurul Falah maka permasalahan yang dihadapi oleh mitra dalam hal ini adalah belum maksimalnya peranan sekolah dalam menekankan pemahaman MEA terhadap anak didik siswa-siswi di SMK Nurul Falah dan sangat pentingnya Pemahaman MEA terhadap anak didik siswa-siswi SMK Nurul Falah, sehingga hal ini merupakan suatu kelemahan atas anak didik siswa-siswi SMK Nurul Falah, juga dapat membawa ancaman dan ketidaksiapan siswa-siswi dalam menghadapi global MEA walaupun telah memiliki Ketrampilan dari SMK Nurul Falah.

\section{METODE}

Dalam rangka mencapai apa yang menjadi tujuan pengabdian pada masyarakat ini, maka pelaksanaan kegiatan pengabdian masyarakat ini dilakukan dengan metode yang sistematis dengan langkah-langkah sebagai berikut :

Memberikan ceramah, penyuluhan, pemberdayaan, diskusi dan Evaluasi yaitu ; Mengenai Latar Belakang Sejarah berdirinya MEA, Ruang lingkup MEA, posisi dan keberadaan MEA saat ini, Posisi dan keberadaan Indonesia saat ini terhadap MEA, posisi dan keberadaan siswa-siswi saat ini dalam menghadapi MEA, Ancaman, Peluang, kelemahan dan kekuatan siswasiswi saat ini dalam menghadapi MEA di Bidang Akuntansi, kesiapan, ketrampilan dan ketahanan yang wajib dimiliki siswa-siswi dalam menghadapi MEA di Bidang Akuntansi, materi Akuntansi yang wajib dan harus mereka kuasai untuk menghadapi MEA.

\section{HASIL}

Mahasiswa SMK Nurul Falah memiliki Jurusan Akuntansi, selama pengabdian dilapangan pemahaman siswasiswi SMK Nurul Falah tidak memahami materi dan ketrampilan yang harus mereka miliki dalam menghadapi MEA di bidang Akuntansi. Tetapi pemahaman mengenai MEA sejarah umum telah mereka pahami.

Kurangnya pemahaman siswa-siswi SMK Nurul Falah ini dibidang pemahaman dan keterampilan yang harus mereka kuasai dapat diatasi melalui peningkatan pemahaman dan pengetahuan siswa-siswi SMK Nurul Falah ini melalui pengabdian yang dilakukan oleh Tim Pengabdian Fakultas Ekonomi Universitas Lancang Kuning.

Tim memberikan pengetahuan dan wawasan secara luas dan mendalam dengan membedah lebih dalam dan luas mengenai kondisi dan situasi pasar bebas tenaga kerja professional saat ini di dikaitkan dengan yang akan dihadapi oleh lulusan-lulusan SMK Nurul Falah khususnya di bidang Akuntansi.

Tim memberikan pengetahuan dan pemahaman mengenai persiapan-persiapan yang harus diper siapkan oleh siswa-siswi dalam menjaga ketahanan tantangan pasar bebas tenaga kerja kedepannya.

Tim memberikan wawasan meningkatkan ketrampilan untuk menghadapi MEA, prioritas yang harus dimiliki oleh siswa-siswi dalam menghadapi MEA. Serta peningkatan wawasan dan pengetahuan yang harus dimiliki oleh siswa-siswi SMK Nurul Falah jika ingin mampu bersaing dan memenangkan kompetisi di pasar bebas tenaga kerja di MEA.

Dengan melalui pengadian ini memperkuat persiapan daya saing siswasiswi dalam menghadapi MEA, dengan cara telah disiapkan mulai dari saat ini, dari 
kelas $1 \mathrm{SMK}$, sehingga pada saat kuliah dan berada di pasar bebas tenaga kerja siswasiswi telah matang memiliki ketrampilan, penguasaan materi akuntansi, penguasaan ketrampilan pendukung lainnya dan kekuatan untuk memiliki mental dalam menghadapi persiapan MEA dan menghadapi MEA.

Adanya MEA membawa kesempatan besar bagi semua tenaga kerja warga negara ASEAN dan tentunya membawa sejumlah peluang dan tantangan. Sebagai contoh, seseorang yang berwarga Negara Indonesia dapat bekerja di Singapura, Thailand, Malaysia, Filipina, Vietnam dan lain-lain. Secara kuantitatif, Indonesia memiliki keunggulan dibandingkan beberapa negara lain, sehingga dapat memaksimalkan kesempatan ini. Namun di sisi lain, Indonesia akan dihadapkan dengan berbagi ancaman apabila Sumber Daya Manusia (SDM) belum siap. Artinya peluang kerja akan diambil oleh tenaga kerja asing dan Indonesia akan menjadi penonton di negeri sendiri.

Lebih spesifiknya MEA membuka pasar bebas tenaga kerja profesional. Ada delapan profesi yang dibuka (free of skill labour) saat MEA mulai bergulir yaitu insinyur, arsitek, perawat, tenaga survei, tenaga pariwisata, praktisi medis, dokter gigi, dan akuntan. Dibukanya delapan profesi tersebut untuk tenaga asing berpotensi mendorong peningkatan pengangguran dari kalangan terdidik.

Mengasah kemampuan dan ketrampilan mulai dari masa SMK kelas 1 untuk membuat lebih kompeten terhadap kemampuan dan ketrampilan untuk bersaing dengan tenaga kerja asing.

Dengan memulai bidang Akuntansi dari SMK sangat membantu siswa-siswi dalam mempermudah dimasa perkuliahan dengan bidang yang sama yaitu Akuntansi.

Dalam memenangkan persaingan di era MEA, setidaknya ada area bagi akuntan yang perlu dikembangkan atau hal-hal yang sangat dibutuhkan dalam persiapan menghadapi MEA dan ketahanan dalam bersaing dengan pasar bebas tenaga kerja dibutuhkan persiapan dalam beberapa hal yaitu ;

\section{Meningkatkan Soft Skill}

Tantangan tersendiri bagi akuntan dan semakin berat bagi mereka yang tidak memiliki skill yang memadai. Modal softskill yang harus dimiliki untuk menghadapi MEA adalah Kemampuan berbahasa asing, kecepatan mengelola teknologi, dan etos kerja yang tinggi.

soft skills terdiri dari 2 bagian yaitu:

1. Interpersonal skills: leadership, motivasi, komunikasi efektif, negosiasi, problem solving.

2. Intra-personal skills: integritas, profesional, character building, creative thinking.

\section{Meningkatkan Kompetensi}

Selain soft-skill, kemampuan dibidang profesionalpun tidak kalah pentingnya. Seorang akuntan yang ingin profesinya diakui dalam level ASEAN harus melalui ASEAN Charter Professional Accountant (ACPA). Jika akuntan Indonesia tidak siap dalam menghadapi MEA, maka akuntan dari negara lain yang akan datang ke Indonesia. Terlebih lagi Indonesia memiliki potensi market jasa akuntansi yang sangat besar. Tentu saja hal ini dapat menggeser kedudukan akuntan Indonesia.

Tenaga akuntan harus mempersiapkan diri dengan mengikuti sertifikasi profesi. Melalui sertifikasi profesi ini, akuntan Indonesia didorong untuk kreatif, inovatif, terampil, dan memiliki daya saing yang tinggi. Knowledge dan skill yang dibutuhkan oleh akuntan profesional akan terus berkembang dengan pesat. Peran organisasi profesi sangat penting dalam menghadapi tantangan ini. Akuntan Indonesia harus siap dan mampu menjadi tenaga yang handal dan mampu bersaing di tingkat internasional.

\section{Membangun Networking}

Di sini akuntan melakukan proses aktif membangun dan mengelola hubunganhubungan yang produktif. Jejaring 
merupakkan hubungan yang luas dan kokoh baik personal maupun organisasi. Selanjutnya dikatakan jejaring dalam organisasi merupakan suatu proses pemeliharaan, penumbuhan serta pengintegrasian kemampuan-kemampuan terpilih, bakat-bakat, hubungan dan partner dengan cara mengembangkan kemitraan yang kreatif dan strategis untuk meningkatkan kinerja organisasi.

Seorang akuntan dituntut mempunyai jaringan dan acuran standar internasional. Jaringan ini penting karena seorang akuntan harus bisa mempromosikan dirinya agar bisa eksis di ASEAN. Sedangkan akuntan harus up to date dengan kondisi terbaru akuntansi yang dijadikan patokan internasional.

\section{Memiliki Sertifikasi Akuntan Professional}

Untuk menjaga profesionalisme dan kompetensi dalam menghadapi MEA, akuntan Indonesia dituntut untuk menjaga dan meningkatkan kapabilitas keilmuannya. akuntan wajib mengikuti Program Pendidikan Berkelanjutan (PPL) yang diselenggaraan oleh IAI, PPAJP, dan/atau pihak lain yang diakui IAI dan/atau Pusat Pembinaan Akuntansi dan Jasa Penilai (PPAJP).

\section{Memiliki Integritas Yang Tinggi}

Integritas merupakan salah satu kode etik akuntan Indonesia untuk memelihara dan meningkatkan kepercayaan public, setiap anggota harus memenuhi tanggung jawab profesionalnya dengan integritas setinggi mungkin. Integritas adalah suatu elemen karakter yang mendasari timbulnya pengakuan profesional.

\section{Mempersiapkan Mental Menjadi Player}

Akuntan harus mempunyai mental "player" bukan "victim", mental player akan menjadikan para akuntan optimis menghadapi MEA, dan tidak gentar dengan akuntan asing. Sedangkan mental victim hanya menjadi jago kandang yang bisa tergilas oleh masuknya akuntan asing. Rekomendasi yang diberikan oleh Tim Pengabdian kepada sekolah adalah dilakukannya beberapa hal dalam mendukung dan mensupport atas persiapan kemampuan dan ketrampilan yang dilandasi dengan kompetensi Bidang Akuntansi dalam ketahanan menghadapi MEA.

SMK Nurul Falah dapat melakukan :

1. Sinkronisasi kurikulum

2. Mengurangi gap antara kurikulum dengan kebutuhan dunia bisnis.

3. Membekali mahasiswa dengan soft skills yang mencukupi.

4. Memberi keterampilan bahasa asing yang mencukupi

\section{PEMBAHASAN}

Telah terpenuhinya pemahaman atas pengetahuan, materi dan keterampilan yang harus mereka kuasai dan miliki dalam menghadapi MEA di bidang Akuntansi. Telah terpenuhinya Pemahaman atas peluang dan tantangan atas pasar bebas tenaga kerja MEA bidang akuntansi. Meningkatkan motivasi untuk membangkitkan rasa percaya diri siswasiswi dalam mengambil pendidikan akuntansi. Meningkatkan minat para siswa untuk mengambil perkuliahan akuntansi. Mendorong siswa-siswi untuk mempersiapkan ketrampilan dan kemampuan bersaing mulai dari sekolah SMK. Menambah wawasan Tim Pengabdian Fakultas Ekonomi Universitas Lancang Kuning melalui pertukaran dan diskusi dengan para siswa. Mengikat keikutsertaan Sekolah dalam mempersiapkan siswa-siswi dalam menghadapi MEA.

Hal ini sejalan dengan apa yang disampaikan oleh Hardi, H., \& Zaharman, Z. (2018) bahwa melalui peningkatkan kemampuan SDM dapat merupakan bentuk strategi dalam menghadapi MEA.

\section{SIMPULAN}

Siswa dan siswi mengenal MEA secara umum, namun tidak mengenal dan memahami MEA secara dalam. Pemahaman atas pengetahuan dan wawasan serta ketrampilan yang harus disiapkan dan dimiliki siswa-siswi harus dimulai dari 
masa sekolah di SMK. Siswa-siswi harus memiliki ketrampilan dan kompetensi diluar yang didapat di sekolah untuk mempertajam kemampuan bersaing dengan pasar bebas tenaga kerja MEA ini.

Siswa-siswi harus memiliki ketrampilan dan kompetensi diluar yang didapat di sekolah untuk mempertajam kemampuan bersaing dengan pasar bebas tenaga kerja MEA ini. Sekolah SMK ikut serta dalam mendukung dan mensupport atas persiapan kemampuan dan ketrampilan yang harus dimiliki oleh siswa-siswi yang dilandasi dengan kompetensi Bidang Akuntansi dalam ketahanan menghadapi MEA.

\section{DAFTAR RUJUKAN}

Hardi, H., \& Zaharman, Z. (2018). Strategi Pemerintah Kota Pekanbaru Dalam Pemberdayaan Dan Pembinaan Umkm Menghadapi MEA. Jurnal Daya Saing, 4(1), 36-47.

Gobel, Rachmat. (2015). Fokus. Masyarakat Ekonomi ASEAN Segera Datang, hlm. 8-10.

Primasanto, T. A,. (2010). Pengiriman Tenaga Kerja Terampil Indonesia ke Luar Negeri : Pelajaran dari Filipina. Jural Diplomasi.Vol 2 No. 1

Robbins, Stephen P. (2002). PrinsipprinsipPerilaku Organisasi. Edisi 5. Jakarta : Erlangga.
Suatma, Jasa. (2012). Kesiapan Indonesia dalam Menghadapi ASEAN Economic Community 2015. Jurnal STIE Semarang, VOL 4, I (1): 1-7.

Triani, Ni Nyoman Alit., Erlina Diamastuti, dan Merlyana Dwinda Yanthi. (2014). Kesiapan Profesi Akuntan di Indonesia dalam Menghadapi MEA. I (1): 3-8. 